\title{
An endoevaporitic microbial mat within a gypsum crust: zonation of phototrophs, photopigments, and light penetration
}

\author{
Aharon Oren ${ }^{1, *}$, Michael Kühl ${ }^{2}$, Ulf Karsten ${ }^{2}$ \\ ${ }^{1}$ Division of Microbial and Molecular Ecology, and the Moshe Shilo Center for Marine Biogeochemistry, \\ Institute of Life Sciences, The Hebrew University of Jerusalem, 91904 Jerusalem, Israel \\ ${ }^{2}$ Max-Planck Institute for Marine Microbiology, Microsensor Group, Fahrenheitstraße 1, D-28359 Bremen, Germany
}

\begin{abstract}
We characterized a layered community of cyanobacteria and purple bacteria that developed within a gypsum crust on the bottom of a hypersaline saltern pond (salinity 280 to $290 \mathrm{~g} \mathrm{l}^{-1}$ ) in Eilat, Israel. The upper 1 to $2 \mathrm{~cm}$ of the 4 to $5 \mathrm{~cm}$ thick gypsum crust is inhabited by carotenoid-rich unicellular cyanobacteria (Aphanothece sp. and others), imparting an orange-brown color to the gypsum. Under the brown layer, a green layer dominated by unicellular cyanobacteria of the genus Synechococcus is found, with filamentous Phormidium-type cyanobacteria as a minor component. Below these layers of oxygenic phototrophs is a red layer of purple bacteria. We studied the optical properties of the gypsum crust, both by characterization of the pigments present in the different layers and by measuring spectral scalar irradiance at different depths in the crust, using fiber-optic microprobes. In the upper $2 \mathrm{~mm}$ of the crust, a maximum of scalar irradiance of up to $200 \%$ of incident light was measured. Light in the blue range of the spectrum (400 to $500 \mathrm{~nm}$ ) was effectively absorbed by the protective carotenoids (myxoxanthophyll, echinenone, and others) in the upper brown layer. However, significant amounts of light in the red part of the spectrum penetrated down to the green layer to enable photosynthesis: about $1 \%$ of the incident irradiance at 620 and $675 \mathrm{~nm}$ reached the green layer at a depth of $15 \mathrm{~mm}$, and $>1 \%$ of the incident light in the infrared part of the spectrum reached the purple bacteria located at a depth of 20 to $23 \mathrm{~mm}$.
\end{abstract}

KEY WORDS: Cyanobacteria $\cdot$ Purple bacteria $\cdot$ Gypsum $\cdot$ Endoevaporitic microbial mat $\cdot$ Carotenoids Scalar irradiance

\section{INTRODUCTION}

Dense stratified communities of photosynthetic microorganisms are often found in coastal marine areas (Stal et al. 1985, Pierson et al. 1990). These photosynthetic microbial mats occur in the top layers of coastal sediments, where microorganisms and sediment particles are embedded in an extracellular polymer matrix. The mats exhibit a vertical stratification of different colored layers, due to the presence of photosynthetic microalgae and bacteria containing different photosynthetic pigments with depth. Cyanobacteria

•E-mail: orena@shum.cc.huji.ac.il and diatoms are generally the predominant component in the upper layers.

Stratified microbial mats are also commonly found at elevated salinities in hypersaline lakes (Jørgensen et al. 1983) and solar salterns (Javor 1989). When different minerals precipitate due to evaporation of the overlaying water, with a concomitant increase in ionic concentrations, the hypersaline mats may also contain mineral crystals, such as aragonite (Jørgensen et al. 1983), gypsum (Caumette 1993, Caumette et al. 1994), and even halite (Rothschild et al. 1994). A cyanobacterial mat was characterized from an evaporite gypsum $\left(\mathrm{CaSO}_{4} \cdot 2 \mathrm{H}_{2} \mathrm{O}\right)$ crust in saltern ponds in the south of France: underneath a layer of unicellular cyanobacteria (Aphanothece halophytica) a 5 to $20 \mathrm{~mm}$ thick layer 
of gypsum crystals was found, below which another cyanobacterial layer, this time consisting of Phormidium-type filaments, developed. A red layer of purple sulfur bacteria was found in the anoxic zone below the cyanobacterial layers (Caumette 1993, Caumette et al. 1994).

On the bottom of a hypersaline saltern pond in Eilat, Israel, massive gypsum deposition has taken place during the last $8 \mathrm{yr}$, and conspicuously pigmented photosynthetic prokaryotes have developed at different depths in this crust, resulting in the formation of colored layers. In contrast to the gypsum crusts described by Caumette et al. (1994), here the microorganisms are embedded within the gypsum matrix, a situation resembling the mixed $\mathrm{NaCl}-g y p s u m$ evaporites of Guerrero Negro, Baja California, Mexico. There photosynthetic prokaryotes were found within the salt crust, and the term 'endoevaporitic community' was coined to describe the phenomenon (Rothschild et al. 1994).

The Eilat gypsum crust is particularly suited as a model system for studies on light absorption by layered photosynthetic microbial communities. Not only are the cells fixed in a solid matrix, preventing disturbance of the stratification during measurements due to migration, but thanks to the absence of significant amounts of abiotic light-absorbing particles, photosynthetically available light penetrates to great depths in the crust, and the light field experienced by the celis is thus mainly dependent on the distribution and nature of the photosynthetic pigments present in the higher layers

In the present report we describe the layered photosynthetic community of the Eilat gypsum crust, with special emphasis on the photosynthetic pigments present, and the spectral light field that exists at different depths within in the gypsum crust.

\section{MATERIALS AND METHODS}

Sampling and characterization of the microbial community in the crust. Gypsum crust was sampled during the period February to October 1994 from the bottom of the southern end of saltern pond No. 203 of the solar salt facility at Eilat, Israel (Lazar \& Erez 1992). Pieces 5 to $10 \mathrm{~cm}$ in diameter were collected, and stored in polyethylene bags in the dark until analysis - generally within $24 \mathrm{~h}$ of sampling. Samples from the colored layers were examined in a Zeiss standard microscope, equipped with phase optics and an Olympus model PM-10AK camera. Protein was analyzed by adding cold 10\% trichloroacetic acid to portions of gypsum crust, collecting the precipitated material on glass fiber filters (Whatman
GF/C), and assaying protein by the method of Lowry et al. (1951).

Measurements of in vivo absorption spectra. For the measurement of in vivo absorption spectra, the individul layers were separated with a spatula, and the material was transfered to a saturated sucrose solution, whereafter the absorption spectrum was recorded in a Varian DMS 100 S UV-visible spectrophotometer equipped with a diffuse reflectance accessory.

Pigment extraction and characterization. Material from the different layers was collected by cutting small pieces of the crust with a knife. These samples (about 0.8 to $1 \mathrm{~g}$ wet $\mathrm{wt}$ ) were homogenized with a mortar and pestle, and extracted with ice-cold $100 \%$ acetone. All steps were done under dim light. Following extraction, homogenates were centrifuged at $4000 \times g$ for $5 \mathrm{~min}$. Supernatants were transferred to graduated tubes and filled up to $5 \mathrm{ml}$ with $100 \%$ acetone. Aliquots $(1 \mathrm{ml})$ of these pigment extracts were evaporated under a stream of nitrogen and redissolved in $50 \mu \mathrm{l} 100 \%$ acetone. Pigments were analyzed by high-performance liquid chromatography (HPLC), using a Waters Associates HPLC setup, including a $600 \mathrm{E}$ gradient module with system controller, and a Model 991 photodiode array detector. Sample volumes of $20 \mu$ l were injected onto the column through a Rheodyne injection valve. Separations were performed on a stainless steel Merck LiChrospher RP 18 cartridge ( $5 \mu \mathrm{m}$ packing, $125 \times 4 \mathrm{~mm}$ internal diameter) after passing through a Merck RP 18 guard column $(4 \times 4 \mathrm{~mm})$. Pigments were eluted by a binary gradient system of helium-degassed solvents and monitored at $436 \mathrm{~nm}$. Absorption spectra were recorded each second between 400 and $800 \mathrm{~nm}$ directly on the HPLC-separated peaks. The mobile phase of solvent A (distilled water) and solvent B (acetonitrilemethanol-tetrahydrofuran, 75:15:10, vol/vol) was regulated at a flow rate of $2 \mathrm{ml} \mathrm{min}^{-1}$ by using the following program: 0 to 10 min for a linear increase from $12 \%$ solvent $A$ and $88 \%$ solvent $B$ to $100 \%$ solvent $B$, and 10 to $18 \mathrm{~min}$ at $100 \%$ solvent $\mathrm{B}$.

The individual pigments of the different gypsum layers were identified by their characteristic absorption maxima in a mixture of solvent $A$ and $B$ corresponding to the appropriate retention time, and quantified by peak area. Identification of the pigments was verified by cochromatography with commercially available standards (Sigma Chemical Co.), or with pigments isolated from pure cultures of the cyanobacterium Scytonema japonica and the purple bacterium Rhodospirillum rubrum. For each compound a molar extinction coefficient was determined, which corresponded to the chromatographic conditions used (Table 1).

Spectral light penetration. Microscale spectral light measurements were performed at a spatial resolution of 
Table 1. Retention time and the molar extinction coefficients $(E)$ for the separated pigments determined at $436 \mathrm{~nm}$

\begin{tabular}{|lcc|}
\hline Pigment & $\begin{array}{c}\text { Retention time } \\
\text { (min) }\end{array}$ & $\begin{array}{c}E \\
\left(\mathrm{mM}^{-1} \mathrm{~cm}^{-1}\right)\end{array}$ \\
\hline Myxoxanthophyll & 2.59 & 69.2 \\
Zeaxanthin & 4.74 & 83.2 \\
Canthaxantin & 5.78 & 143.9 \\
Spirilloxanthin & 9.63 & 52.3 \\
Bacteriochlorophyll a (bchl a) & 10.1 & 4.9 \\
Echinenone & 10.94 & 75.3 \\
Rhodovibrin & 11.44 & not determined \\
Chlorophyll a (chl a) & 12.37 & 91.7 \\
B-Carotene & 15.42 & 125.3 \\
Phaeophytin a & 16.2 & 22.7 \\
& & \\
\hline
\end{tabular}

1 to $2 \mathrm{~mm}$, using fiber-optic microprobes for scalar irradiance. Depth profiles of spectral scalar irradiance, i.e. the spherically integrated total quantum flux from all directions, were measured by a fiber-optic microprobe, consisting of a small diffusing sphere of $\mathrm{TiO}_{2}$-doped methacrylate, cast on the tapered tip of a chromiumcoated optical fiber (Lassen et al. 1992). This type of probe has an isotropic response for incident light (Kühl et al. $1994 \mathrm{~b}$ ), and has a tip diameter of 50 to $100 \mu \mathrm{m}$. The fiber-optic microprobes were inserted at a zenith angle of $60^{\circ}$ relative to the incident collimated light beam into the gypsum crust through a preformed hole made with a 20 gauge injection needle. The gypsum crust remained immersed in brine from the saltern pond during these experiments. The position of the microprobes was controlled by a manually operated micromanipulator. Homogeneous vertical illumination was provided by a fiber-optic tungsten-halogen light source (Schott KL1500 ), equipped with a collimating lens. The fiber-optic microprobes were connected via an optical coupling to an optical spectral multichannel analyzer (OSMA, Spectroscopy Instruments), consisting of an intensified diode array detector unit (Princeton Instruments, EIRY-1024) coupled to a spectrograph (Jarrel Ash, SA-16). Spectral scalar irradiance between 430 and $880 \mathrm{~nm}$ was measured with a spectral resolution of 2 to $5 \mathrm{~nm}$. Further details about the light detection system are given by Kühl \& Jørgensen (1992).

\section{RESULTS}

\section{Structure and zonation of phototrophs}

The bottom of the southern end of saltern pond 203 is covered with a gypsum crust (Fig. 1, upper panel). This crust, with an average thickness of $4 \mathrm{~cm}$, formed during a 8 yr period in which the salinity of the pond was kept at around $160 \mathrm{~g} \mathrm{l}^{-1}$. As a result of changes in the operation of the saltern facility, the crust is now found below a shallow $(10$ to $20 \mathrm{~cm}$ ) layer of brine with a density of $1.17 \mathrm{~g} \mathrm{~cm}^{-3}$, corresponding to a total dissolved salt content of $286 \mathrm{~g} \mathrm{l}^{-1}$ (Lazar \& Erez 1992). The gypsum material had a specific gravity of about 1.6 to $1.65 \mathrm{~g} \mathrm{~cm}^{-3}$, and a dry wt content of $72.1 \pm 2.2 \%$.

A cross-section through a piece of gypsum disclosed a layered endoevaporitic microbial community (Fig. 1, lower panel). Microscopic examination showed the upper 10 to $20 \mathrm{~mm}$ of the crust to be inhabited by 2 types of carotenoid-rich unicellular cyanobacteria (Fig. 2A,B), imparting an orange-brown color to the gypsum. Similar cyanobacteria have been described from hypersaline sites all over the world, and have been designated with different names: Cyanothece (Margheri et al. 1987, Caumette et al. 1994), Aphanothece halophytica (Brock 1976, Javor 1989, Caumette et al. 1994), and Synechococcus sp. (Rothschild et al. 1994), using the classification scheme proposed by Rippka et al. (1979). In addition, unicellular green algae Dunaliella sp. and ciliate protozoa were occasionally seen, and nonphotosynthetic bacteria were very abundant in the brown layer. All these microorganisms were embedded in massive amounts of mucoid polysaccharides excreted by the cyanobacteria (De Philippis et al. 1993, Caumette et al. 1994).

A second layer, found ca $15 \mathrm{~mm}$ below the surface, was green, and was dominated by cyanobacteria of the genus Synechococcus, with filamentous Phormidiumtype cyanobacteria as a minor component (Fig. 2C). Below these layers of oxygenic phototrophs a 3 to $10 \mathrm{~mm}$ thick red layer of purple bacteria was found, in which 2 dominant types of cells could be recognized. The first was a motile purple sulfur bacterium with intracellular sulfur granules (Fig. 2E) (Chromatium sp., probably $C$. salexigens, which has been isolated from a similar habitat) (Caumette et al. 1988, Caumette 1993). The second abundant type consisted of small spirally shaped bacteria (Fig. 2F). These may either be sulfideoxidizing photosynthetic bacteria belonging to the genus Ectothiorhodospira, representatives of which have been isolated from saltern ponds (Ventura et al. 1988, Imhoff 1992), or may be purple nonsulfur bacteria similar to Rhodospirillum salinarium, which was reported to occur at high densities in certain saltern sediments (Nissen \& Dundas 1984). In many cases a thin whitish layer was observed between the green and the red layers, in which spherical bacteria with refractile inclusions were observed (Fig. 2D). These bacteria are probably colorless sulfur bacteria, and resemble the Achromatium described from a hypersaline diatom mat on the bottom of Solar Lake, Sinai (Jørgensen et al. 1983). Below the red layer, the crust was black, due to iron sulfide precipitation induced by bacterial sulfate reduction. 

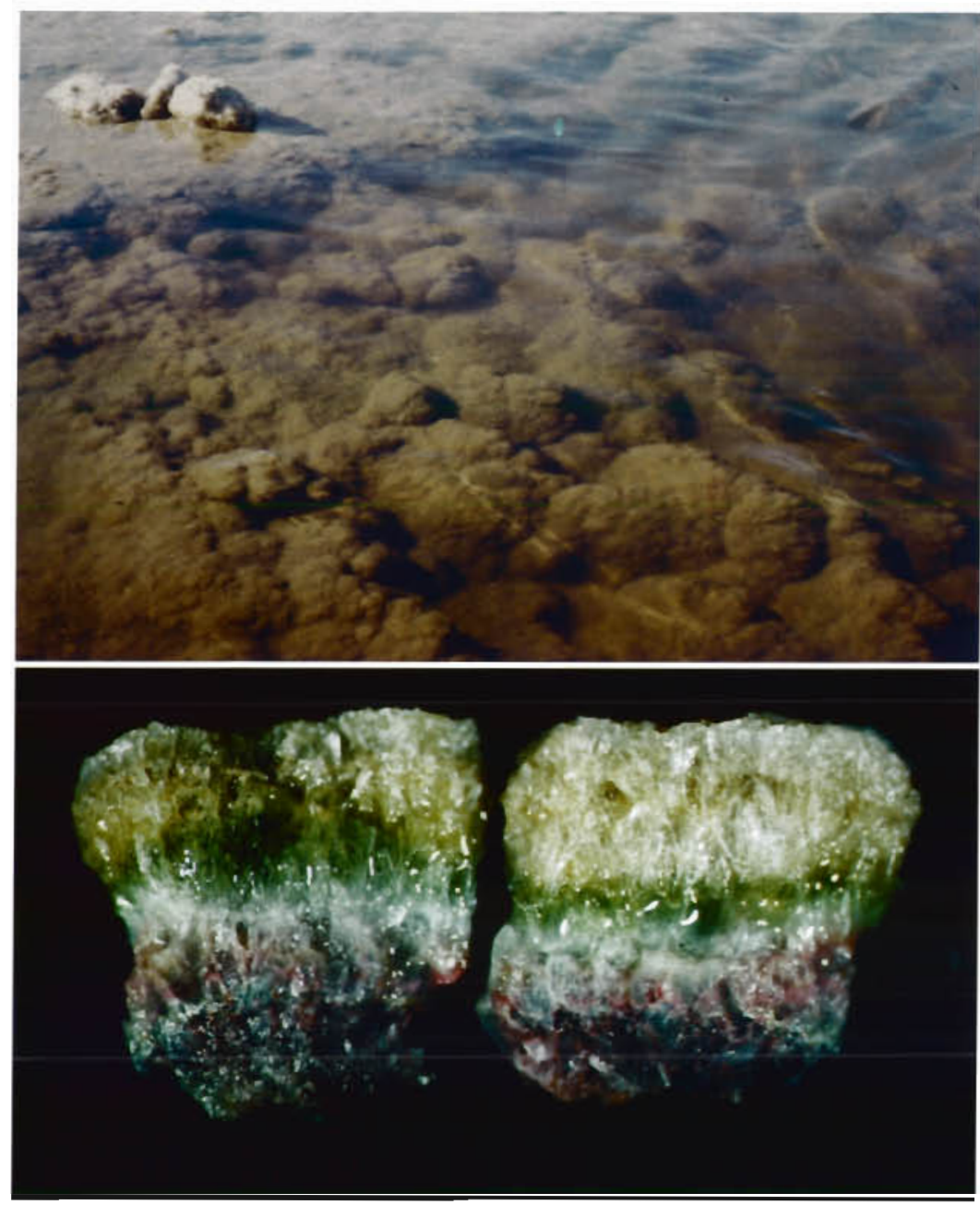

Fig. 1. Part of the gypsum-covered bottom of Eilat saltern pond 203 (upper panel), and a cross-section through a $4 \mathrm{~cm}$ thick piece of the gypsum crust, showing endoevaporitic layered microbial communities (lower panel)

The photosynthetic community in the gypsum crust represents a high biomass. Protein measurements yielded values between 0.47 and $0.75 \mathrm{mg} \mathrm{cm}^{-3}$ in the orange-brown upper layer, and up to $1.9 \mathrm{mg} \mathrm{cm}^{-3}$ in the green layer.

\section{In vivo spectra}

The upper orange-brown layer was characterized by a strong absorption in the blue region of the spectrum (440 to $520 \mathrm{~nm}$ ), due to a high content of carotenoid pigments. No pronounced phycocyanin absorption peak was seen, and the chlorophyll a (chl a) peak in the red part of the spectrum (670 to $675 \mathrm{~nm}$ ) was small relative to the large biomass present. The green layer had a lower carotenoid content, and more pronounced chl $a$ and phycocyanin peaks. The absorption spectrum of the red layer was dominated by bacteriochlorophyll a (bchl a) and carotenoids characteristic of purple bacteria, mainly spirilloxanthin. The same features can be seen in absorption spectra of pigment extract in organic solvents, which showed, however, a pronounced band shift of the bchl a peak, and did not show the phycocyanin peak, as this pigment is not extracted in the procedure used (Fig. 3, right panels).

\section{Pigment analysis}

Pigments extracted from the $3 \mathrm{col}$ ored layers were further characterized by HPLC, and identified and quantified according to their retention times, absorption spectra, and molar extinction coefficients (Fig. 4, Table 1). The dominant pigments in the orange-brown layer were myxoxanthophyll and echinenone, with some $\beta$-carotene, chl $a$ and phaeophytin $\alpha$, and minor amounts of zeaxanthin and canthaxanthin. The presence of minor amounts of bchl $a$ and spirilloxanthin derived most probably from the lower layers during separation of the layers by cutting with a knife. The green layer was characterized by major amounts of myxoxanthophyll, echinenone, $\beta$-carotene and phaeophytin $a_{\text {, }}$ and a high concentration of chl a. Contents of the 3 carotenoids were 2.7- to 7.6 -fold higher in the green layer compared to the orange-brown layer, while chl a values were even 13 times higher. As in the orange-brown layer, minor concentrations of zeaxanthin and canthaxanthin were also encountered in the green layer The red layer exhibited major amounts of spirilloxanthin and bchl a. Okenone, a carotenoid characteristic of certain Chromatium species, was not detected. A minor amount of rhodovibrin was also found, and some $\beta$-carotene, myxoxanthophyll, echinenone and chl a was detected as well, being probably derived from the upper layers during sample preparation as mentioned above. Molar pigment ratios of myxoxanthophyll/chl $a_{\text {, echi- }}$ nenone/chl $a$ and $\beta$-carotene/chl a showed a decrease with depth, ranging from 1.9 to 0.2 for the former, 1.3 to 0.2 for the second, and 0.6 to 0.4 for the latter one (Fig. 5). 


\section{Spectral light penetration}

The scalar irradiance at the surface of the gypsum crust was up to 2 times higher than the incident irradi- ance, dependent on the wavelength, due to the intense light scattering in the gypsum matrix (Fig. 6). Scalar irradiance spectra recorded at different depths in the crust showed that light in the blue range of the spectrum
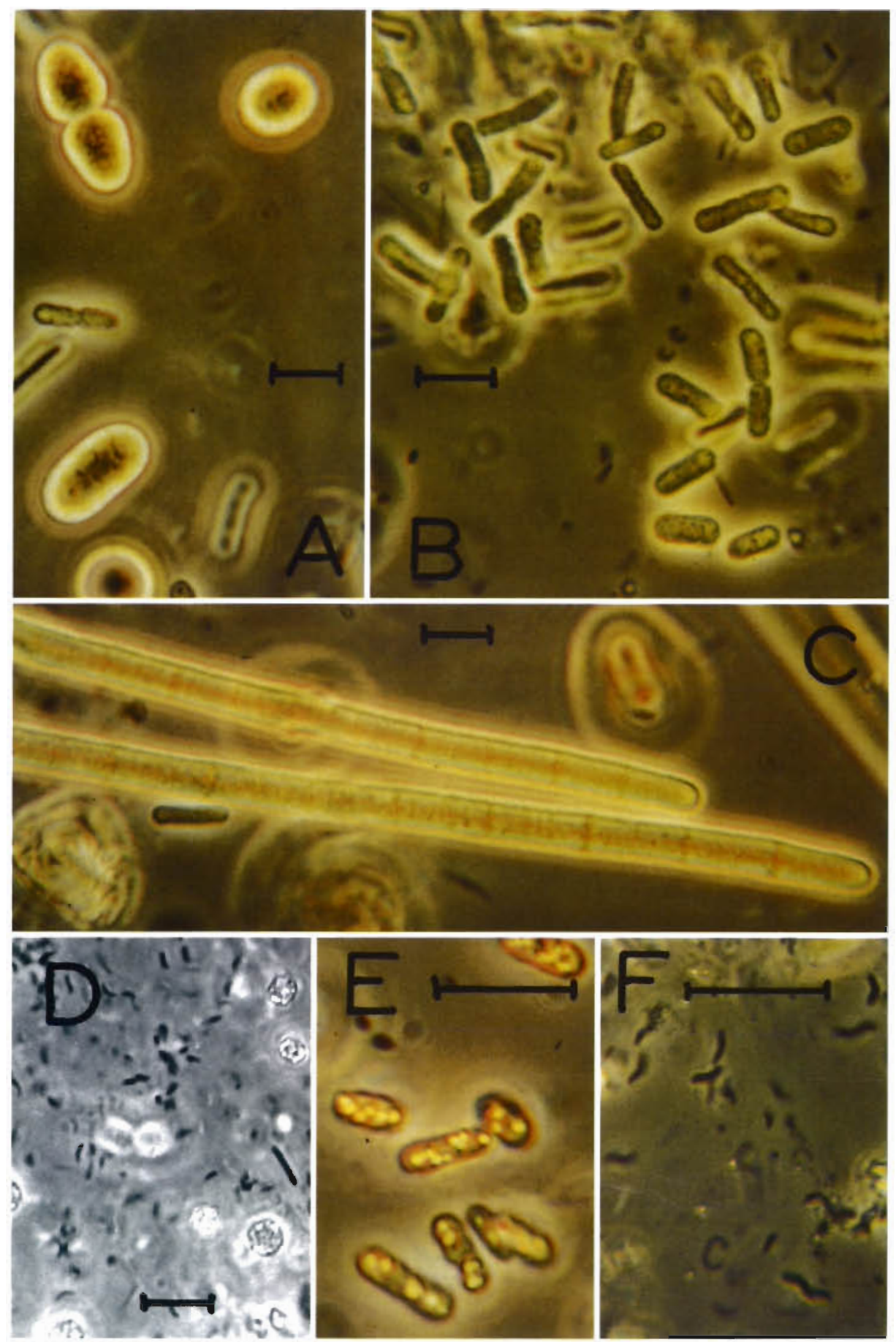

Fig. 2. Microphotographs of cyanobacteria and other bacterial types found in the Eilat gypsum crust: (A, B) unicellular Aphanothece or Synechococcus-type cyanobacteria from the upper brown layer, (C) filamentous Phormidium-type cyanobacteria from the green layer, (D) spherical colorless sulfur bacteria with intracellular sulfur inclusions from the white layer between the green and red layers, and 2 types of purple bacteria from the red layer: (E) Chromatium sp., and (F) small spirilla (probably Ectothiorhodospira sp. or Rhodospirillum salinarium). Phase-contrast; scale bar $=10 \mu \mathrm{m}$ 
(450 to $550 \mathrm{~nm}$ ) was absorbed very efficiently by the carotenoids (myxoxanthophyll, echinenone) in the orange-brown layer, and only ca $0.1 \%$ of the incident blue light reached the top of the green layer (Figs. 6 \& 7). However, significant amounts of light in the red part of the spectrum penetrated down to the green layer to enable photosynthesis (ca $1 \%$ of the incident irradiance at 620 and $675 \mathrm{~nm}$ reached the green layer at a depth of $15 \mathrm{~mm}$ ), and $>1 \%$ of the incident light in the infrared part of the spectrum reached the purple bacterial layer at a depth of 22 to $25 \mathrm{~mm}$ (Figs. 6 \& 7).

\section{DISCUSSION}

The halophilic photosynthetic mat community described in this work is unique due to the 'endoevaporitic' distribution of the microorganisms inside the solid gypsum matrix of the crust. In most other similar evaporitic environments documented so far, the biota were found both above and underneath the gypsum layer, but not within the gypsum layer. Thus, microbial communities comparable to the ones present in the Eilat gypsum crust were found in saltern ponds at salinities between 130 and $300 \%$ in the south of France, but here the unicellular cyanobacteria (Aphanothece sp.) were found on top of the gypsum, and the
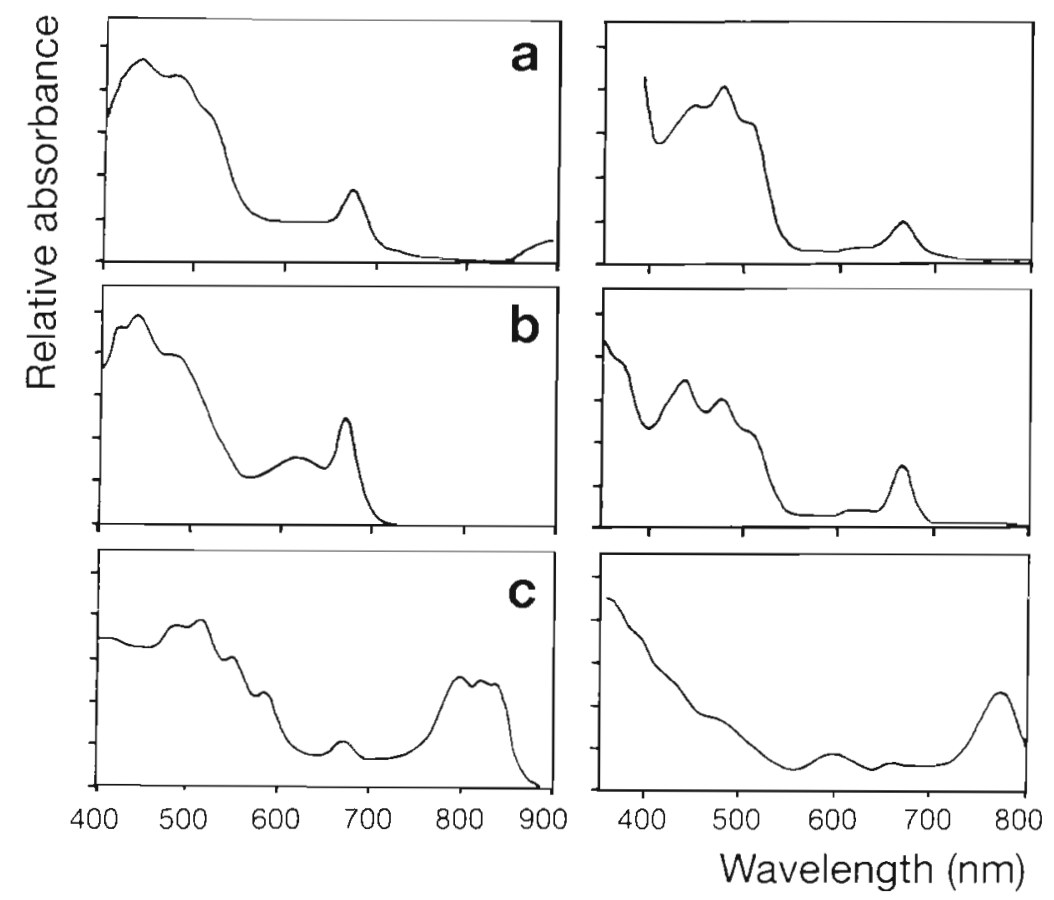

Fig. 3. In vivo absorption spectra of the microbial communities present in the (a) brown, (b) green, and (c) red layers of the gypsum crust (left panels), as measured in suspensions in a saturated sucrose solution, using a spectrophotometer equipped with a diffuse reflectance accessory, and absorption spectra of the pigments extracted in methanol-acetone (1:1, vol/vol) (right panels) green layer, consisiting in this case mainly of filamentous cyanobacteria (Phormidium or Lyngbya), was found below the gypsum (Caumette 1993, Caumette et al. 1994). A somewhat different arrangement of photosynthetic communities was described for the gypsum layers in a saltern system in Spain: there the filamentous Microcoleus chthonoplastes was found in the top layer, with anoxygenic phototrophic bacteria below the gypsum (Clavero et al. 1994). The presence of unicellular cyanobacteria of the Aphanothece-Cyanothece-Synechococcus group is commonly reported in salterns and other hypersaline environments (Brock 1976, Margheri et al. 1987, Javor 1989, Roussomoustakaki \& Anagnostidis 1991). These cyanobacteria excrete massive amounts of polysaccharidic capsular material (Margheri et al. 1987, De Philippis et al. 1993), which holds the community together.

The distribution of the biota in the Eilat gypsum crust can be compared to some extent with the endoevaporitic microbial community found in hypersaline lagoons of Guerrero Negro on the Pacific coast of Baja California Sur (Mexico) (Rothschild et al. 1994). In this case the evaporites consisted of $75 \% \mathrm{NaCl}$, with only $23 \%$ gypsum and $2 \%$ other salts, and had a much lower water content ( 9 to $12 \%$ only), as compared to the crust we investigated. However, even under these extreme conditions a photosynthetic community was present (between 0.16 and $1.79 \mathrm{mg}$ protein and 0.59 and $4.62 \mu \mathrm{g}$ chl a $\mathrm{g}^{-1}$ evaporite) (Rothschild et al. 1994).

The pigments found in the orangebrown, green, and red layers are characteristic for the organisms detected in the respective layers. While cyanobacteria typically contain the carotenoids myxoxanthophyll, echinenone and canthaxanthin, purple sulfur bacteria instead synthesize spirilloxanthin and other characteristic carotenoids. The biological function of pigments in phototrophic organisms is light harvesting, photoprotection, and membrane stabilization (Krinsky 1978, Prezelin 1981, Ourisson \& Rohmer 1982). The second role seems to be very important especially in the orange-brown layer of the crust. This uppermost layer is very often exposed to a surface downwelling irradiance up to $2000 \mu \mathrm{mol}$ quanta $\mathrm{m}^{-2} \mathrm{~s}^{-1}$, and it is reasonable to assume that this surplus of light cannot be utilized by photochemical reactions. To prevent photoinhibition and photodestruction of the photosyn- 


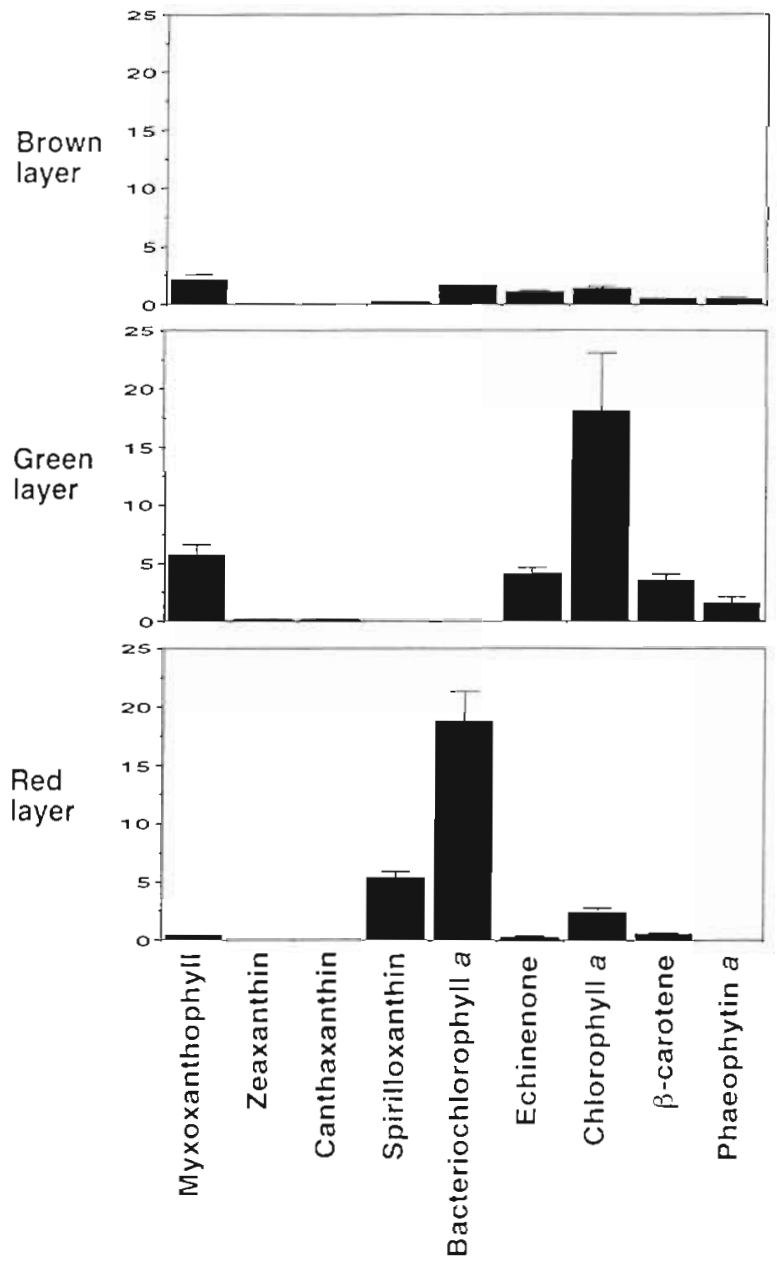

Fig. 4. Quantitation of pigments extracted from the brown, green, and red layers of the gypsum crust. Pigments were separated by HPLC, identified according to their retention times and their absorption spectra, and quantified as $\mathrm{mg} \mathrm{kg}^{-1}$ dry wt according to the molar extinction coefficients given in Table 1

thetic apparatus, the phototrophic organisms in the upper layers of the crust must rely on protective mechanisms for energy dissipation. Carotenoids are well known to fulfil this function by quenching the triplet state of chlorophyll, inactivating harmful singlet oxygen, and serving as an oxidizable substrate to protect other molecules (Krinsky 1978). The occurrence of high myxoxanthophyll/chl a molar ratios in the orange-brown layer supports such a protective role of the carotenoids present.

The green layer exhibited the highest biomass on a protein, as well as on a chl a basis. Similar results have been reported for a gypsum crust in saltern ponds in France (Caumette et al. 1994). The reason why phototrophic organisms of this layer form the proportionally highest biomass is probably related to the moderate light intensity in this depth horizon (Figs. 6 \& 7 ).

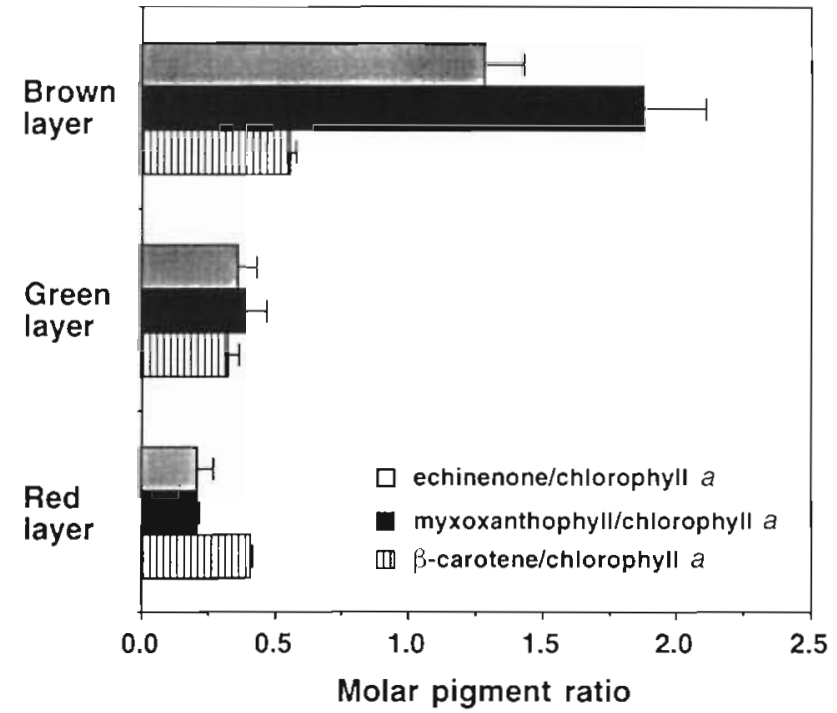

Fig. 5. Molar ratio of echinenone, myxoxanthophyll, and $\beta$ carotene to chl $a$ in the orange-brown, green, and red layers of the gypsum crust

Cyanobacteria isolated from microbial mats prefer low light regimes for growth and development in culture (L. Prufert-Bebout unpubl. results). The high carotenoid content of the upper layer greatly reduced the

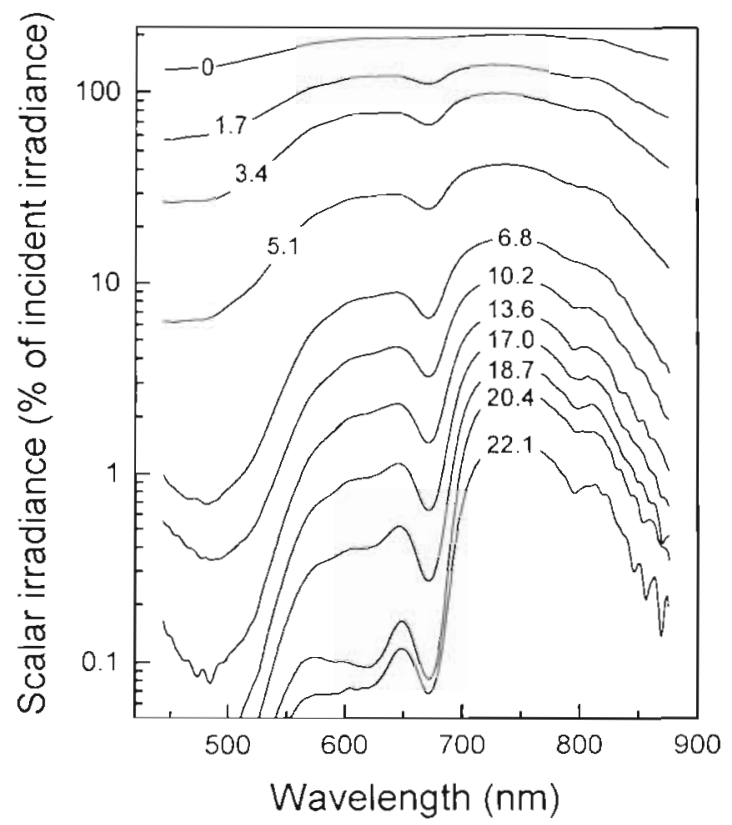

Fig. 6. Spectral light measurements inside the gypsum crust. Scalar irradiance at wavelengths between 430 and $880 \mathrm{~nm}$ was measured at 1 to $2 \mathrm{~mm}$ depth intervals inside the crust. Data were normalized to incident downwelling irradiance at the crust surface. The numbers on the curves indicate the depth in mm below the surface. In the crust examined the orange-brown layer extended down to a depth of $15 \mathrm{~mm}$, the green layer from 15 to $20 \mathrm{~mm}$, and the red layer from 22 to $25 \mathrm{~mm}$ 


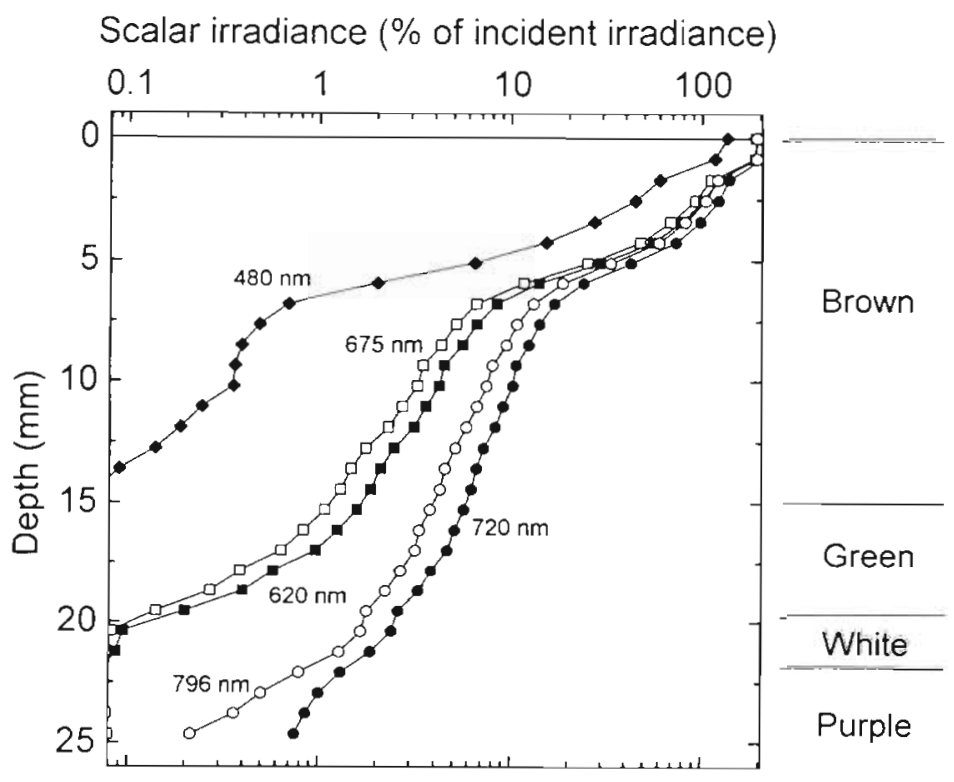

Fig. 7. Depth profiles of scalar irradiance in the gypsum crust for $480 \mathrm{~nm}$ (maximum of carotenoid absorption), $620 \mathrm{~nm}$ (absorbed mainly by phycocyanin), $675 \mathrm{~nm}$ (chl a absorption maximum), $796 \mathrm{~nm}$ (absorbed by bchl a), and $720 \mathrm{~nm}$ (no significant absorption by photopigments). Scalar irradiance is expressed as percentage of the incident irradiance at the sediment surface. The thickness of the different colored layers is indicated on the figure

amount of light reaching the green and red layer underneath, thereby alleviating photoinhibitory effects (Fig. 6).

By use of fiber-optic microprobes it was possible, for the first time, to directly characterize the spectral light field experienced by the biota inside the gypsum crust. The intense scattering and reflection of light in the gypsum matrix and the exopolymers lead to a diffusive light field in which scattered light is a significant component of the total quantum flux available to the phototrophs inside the crust. We measured scalar irradiance which is an integral measure of the total radiant flux from all directions. Our measurements showed that in the upper layers of the crust, scalar irradiance reached up to $200 \%$ of the irradiance incident at the crust surface due to the intense scattering (Figs. $6 \& 7$ ). Similar scalar irradiance maxima have been described for sandy sediments and microbial mats (Kühl \& Jørgensen 1992, Lassen et al. 1992, Kühl et al. 1994a, b). Not only the light intensity but also the spectral composition differed from the incident light at the crust surface, as the component of diffuse scattered light was filtered through part of the crust matrix (Fig. 6). Earlier attempts to measure light penetration were performed by placing layers of various thickness on top of large irradiance detectors. Thus, it was reported that about 0.1 to $0.4 \%$ of the incident irradiance $(400$ to $700 \mathrm{~nm}$ ) reached the purple layer in gypsum crusts from the south of France (Caumette et al. 1994), and in salt crusts from Guerrero Negro, Baja California, approximately $14 \%$ of the incident light ( 400 to $700 \mathrm{~nm}$ ) reached the top of the algal zone (Rothschild et al. 1994). These irradiance measurements probably underestimate the total quantum flux available to the cells.

The spectral analysis system used in the present study yields information on the spectral quality of the light penetrating to the different layers in the Eilat gypsum crust. Similar to what is commonly found in other layered microbial mats (Kühl \& Jørgensen 1992, Kühl et al. 1994a, b), the shorter wavelengths are preferentially absorbed in the upper layer, as expected on account of the high carotenoid content of the upper orangebrown layer. Infrared light penetrates to great depths, and is thus available to the community of purple bacteria located below the oxygenic phototrophs (Fig. 6).

Because of the spectral limitations of the detector system used, we were unable to examine light penetration and absorption of light in the near UV range. We have shown before that the biota in the orange-brown layer of the Eilat gypsum crust contain a high concentration of mycosporine-like amino acids, low molecular weight water-soluble compounds, containing a substituted cyclohexenone or an imino cyclohexene ring. Absorption spectra of extracts of the gypsum crust in $20 \%$ methanol showed a maximum at $332 \mathrm{~nm}$, with a shoulder between 360 and $365 \mathrm{~nm}$. Using HPLC, 2 UV-absorbing compounds were separated, with absorbance peaks at 332 and $362 \mathrm{~nm}$ (A. Oren unpubl. results). It was suggested that these compounds may act as a sunscreen, protecting against solar UV radiation (Garcia-Pichel \& Castenholz 1993). The high concentrations of mycosporine-like amino acids, with intracellular concentrations estimated to be at least $100 \mathrm{mM}$, and possibly much higher, suggest that these compounds may not only function as a sunscreen, but may also have an osmotic function, helping the cells to cope with the high salt concentrations in their environment (A. Oren unpubl. results). Light probes sensitive to UV radiation and a suitable detection system were recently developed (Garcia-Pichel 1995). Such a system will enable the assessment of the possible importance of mycosporine-like amino acids in determining the quality of the light field experienced by photosynthetic communities at different depths within the gypsum crust.

The present study did not attempt to obtain measurements of the photosynthetic activity of the different layers. Such measurements, involving oxygen microelectrodes (Jørgensen et al. 1983, Revsbech 1994) 
would be difficult to perform in the solid gypsum crust. Penetration of the electrodes into the crust requires the drilling of holes, thus changing diffusion characteristics around the electrodes, and creating other artifacts. However, the presence of a large deficit in total dissolved $\mathrm{CO}_{2}$ measured in the brines overlaying the gypsum layer in the Eilat salterns (Lazar \& Erez 1992) provides indirect evidence that intense photosynthetic activity may occur in the endoevaporitic microbial community within the gypsum crust.

Acknowledgements. We thank the Israel Salt Company for allowing access to the Eilat saltern ponds, the staff of the Interuniversity Institute of Eilat for logistic support, and D. Iluz for his help with the operation of the diffuse reflectance spectrophotometer. This work was supported by the Israel Science Foundation administered by the Israel Academy of Sciences and Humanities, the Max-Planck-Gesellschaft, Munich, Germany, and the Moshe Shilo Center for Marine Biogeochemistry, BMFT-Minerva Gesellschaft für Forschung, Munich, Germany.

\section{LITERATURE CITED}

Brock TD (1976) Halophilic blue-green algae. Arch Microbiol 107:109-111

Caumette P (1993) Ecology and physiology of phototrophic bacteria and sulfate-reducing bacteria in marine salterns. Experientia 49:473-481

Caumette P, Baulaigue R, Matheron R (1988) Characterization of Chromatium salexigens sp. nov., a halophilic Chromatiaceae isolated from Mediterranean salinas. Syst appl Microbiol 10:284-292

Caumette P, Matheron R, Raymond N, Relexans JC (1994) Microbial mats in the hypersaline ponds of Mediterranean salterns (Salins-de-Giraud, France). FEMS Microbiol Ecol 13:273-286

Clavero E, Grimault JO, Merino V, Hernandez-Mariné M (1994) Structure of the sediment at depositional saline environments. In: Stal LJ, Caumette P (ed) Microbial mats. Structure, development and environmental significance. Springer-Verlag, Berlin, p 91-96

De Philippis R, Margheri MC, Pelosi E, Ventura S (1993) Exopolysaccharide production by a unicellular cyanobacterium isolated from a hypersaline habitat. J appl Phycol 5:387-394

Garcia-Pichel F (1995) A scalar irradiance fiber-optic microprobe for the measurement of ultraviolet radiation at high spectral resolution. Photochem Photobiol 61:248-254

Garcia-Pichel F, Castenholz RW (1993) Occurrence of UVabsorbing, mycosporine-like compounds among cyanobacterial isolates and an estimate of their screening capacity. Appl environ Microbiol 59:163-169

Imhoff JF (1992) The family Ectothiorhodospiraceae. In: Balows A, Trüper HG, Dworkin M, Harder W, Schleifer $\mathrm{KH}$ (ed) The prokaryotes. A handbook on the biology of bacteria: ecophysiology, isolation, identification, applications, 2nd edn. Springer-Verlag, New York, p 3222-3229

Javor B (1989) Hypersaline environments. Springer-Verlag, Berlin

Jorgensen BB, Revsbech NP, Cohen Y (1983) Photosynthesis and structure of benthic microbial mats: microelectrode

This article was presented by T. Fenchel (Senior Editorial Advisor), Helsingor, Denmark and SEM studies of four cyanobacterial communities Limnol Oceanogr 28:1075-1083

Krinsky NI (1978) Non-photosynthetic functions of carotenoids. Phil Trans R Soc Lond Ser B 284:581-590

Kühl M, Jørgensen BB (1992) Spectral light measurements in microbenthic phototrophic communities with a fiber-optic microprobe coupled to a sensitive diode array detector. Limnol Oceanogr 37:1813-1823

Kühl M, Lassen C, Jørgensen BB (1994a) Optical properties of microbial mats: light measurements with fiber-optic microprobes. In: Stal LJ, Caumette P (ed) Microbial mats. Structure, development and environmental significance. Springer-Verlag, Berlin, p 149-165

Kühl M, Lassen C, Jargensen BB (1994b) Light penetration and light intensity in sandy marine sediments measured with irradiance and scalar irradiance fiber-optic microprobes. Mar Ecol Prog Ser 105:139-148

Lassen C. Ploug H, Jørgensen BB (1992) A fibre-optic scalar irradiance microsensor: application for spectral light measurements in sediments. FEMS Microbiol Ecol 86: $247-254$

Lazar B, Erez J (1992) Carbon geochemistry of marinederived brines: I. ${ }^{13} \mathrm{C}$ depletions due to intense photosynthesis. Geochim cosmochim Acta 56:335-345

Lowry OH, Rosebrough NJ, Farr AL, Randall RJ (1951) Protein measurement with the Folin phenol reagent. $J$ biol Chem 193:265-275

Margheri MC, Tredici MR, Barsanti L, Balloni W (1987) The photosynthetic community of the Trapani saline lagoons: an alternative option for the exploitation of an extreme environment. Ann Microbiol 37:203-215

Nissen H, Dundas ID (1984) Rhodospinllum salinarium, $\mathrm{sp}$ nov., a halophilic photosynthetic bacterium isolated from a Portugese saltern. Arch Microbiol 138:251-256

Ourisson G, Rohmer M (1982) Prokaryotic polyterpenes phylogenetic precursors of sterols. Curr Top Membr Transp 17:153-182

Pierson BK, Sands VM, Frederick JL (1990) Spectral irradiance and distribution of pigments in a highly layered marine microbial mat. Appl environ Microbiol 56 $2327-2340$

Prezelin BB (1981) Light reactions in photosynthesis. Can Bul] Fish Aquat Sci 210:1-43

Revsbech NP (1994) Analysis of microbual mats by use of elec trochemical microsensors: recent advances. In: Stal LJ, Caumette P (ed) Microbial mats. Structure, development and environmental significance. Springer-Verlag, Berlin, p $135-147$

Rippka R, Deruelles J, Waterbury JB, Herdman M, Stanier RY (1979) Generic assignments, strain histories and properties of pure cultures of cyanobacteria. J gen Microbiol 111:1-61

Rothschild LJ, Giver LJ, White MR, Mancinelli RL (1994) Metabolic activity of microorganisms in evaporites. J Phycol 30:431-438

Roussomoustakaki M, Anagnostidis K (1991) Cyanothece halobia, a new planktic chroococcalean cyanophyta from hellenic heliothermal saltworks. Arch Hydrobiol 64:71-95

Stal LJ, van Gemerden H, Krumbein WE (1985) Structure and development of a benthic marine microbial mat. FEMS Microbiol Ecol 31:111-125

Ventura S, De Philippis R, Materassi R, Balloni W (1988) Two halophilic Ectothiorhodospira strains with unusual morphological, physiological and biochemical characters Arch Microbiol 149:273-279

Manuscript first received: January 27, 1995

Revised version accepted: May 8, 1995 